\title{
$\mathbf{R}$

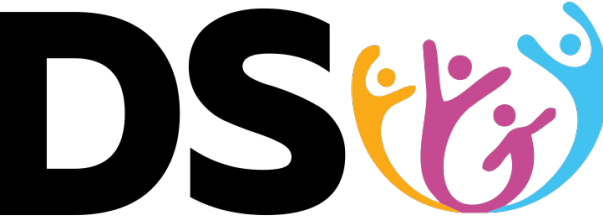

Revista Desenvolvimento Social

\section{O CONTRIBUTO DO ENSINO SUPERIOR PARA O DESENVOLVIMENTO NA ÁFRICA SUBSARIANA: CASOS DE ANGOLA E MOÇAMBIQUE}

\author{
Teresa Patatas ${ }^{1}$ \\ Godwen Veremu²
}

\begin{abstract}
Resumo: África Subsariana é uma região que aposta na educação, em especial o ensino superior, para o seu aspirado desenvolvimento. Neste estudo apresentam-se dois exemplos da contribuição do ensino superior para o desenvolvimento nacional de dois países, Angola e Moçambique, mostrando os casos de duas Instituições de Ensino Superior: Escola Superior Politécnica do Namibe (em Angola) e Instituto Superior Politécnico de Manica (em Moçambique). O objetivo é mostrar como as duas instituições têm contribuído para o desenvolvimento local, e consequentemente nacional, com a sua oferta formativa e evidenciando-se os trabalhos de fim de curso de licenciatura. Fez-se uma pesquisa bibliográfica e documental neste estudo múltiplo de caso, para além de um estudo de documentos institucionais. Os resultados mostram que as duas instituições têm contribuído na formação de quadros e na especialização de mão de obra, através das suas licenciaturas. Nesta pesquisa destacaram-se os trabalhos de fim de curso que visam múltiplos beneficiários e trazem benefícios investigativos, assim como sugestões de melhorias exequíveis com a finalidade de melhor produtividade, qualidade, efetivação e eficácia dos variados recursos disponíveis para um maior impacto no desenvolvimento local e consequentemente nacional.
\end{abstract}

Palavras-chave: África Subsariana; Desenvolvimento nacional; Educação; Ensino superior angolano; Ensino superior moçambicano.

\section{THE CONTRIBUTION OF HIGHER EDUCATION IN THE DEVELOPMENT OF SUB-SAHARAN AFRICA: CASE STUDY OF ANGOLA AND MOZAMBIQUE}

Abstract: Sub-Saharan Africa is a region which opts for education, especially higher education, for its inspired development. In this study two examples of the contribution of higher education in the national development of the two countries, Angola and Mozambique, are presented, showing the cases of two Higher Education Institutions: Escola Superior Politécnica do Namibe (in Angola) and Instituto Superior Politécnico de Manica (in Mozambique). The aim is to show how the two institutions have contributed for the local and consequently national development, with its training offer and evidenced by the undergraduate coursework. Bibliographic and documentary research was done in this multiple case study, besides the study on institutional documents. The results show that the two institutions contribute in the training of staff and in specialization of human labour through their undergraduate degrees. In this research, it was highlighted the graduate coursework which showed multiple beneficiaries and brought research benefits, as well as achievable suggestions for improvement with the

\footnotetext{
${ }^{1}$ Professora, Escola Superior Politécnico do Namibe (atualmente integrada na Universidade do Namibe), Angola. E-mail: teresapatatas.angola@gmail.com.

2 Professor, Instituto Superior Politécnico de Manica (ISPM), Moçambique. E-mail: gsveremo@gmail.com.
} 
aim of better productivity, quality, effectiveness and efficiency of the varied available resources for a higher impact on the local and consequently national development.

Keywords: Sub-Saharan Africa; National development; Education; Angolan higher education; Mozambican higher education.

\section{LA CONTRIBUCIÓN DE LA EDUCACIÓN SUPERIOR PARA EL DESARROLLO DE ÁFRICA SUBSAHARIANA: CASO DE ANGOLA Y MOZAMBIQUE}

Resumen: El África subsahariana es una región que apuesta por la educación, especialmente en la educación superior, para su desarrollo deseado. En este estudio se presentan dos ejemplos de la contribución de la enseñanza superior al desarrollo nacional de dos países, Angola y Mozambique, mostrando los casos de dos instituciones de enseñanza superior: la Escuela Superior Politécnica do Namibe (en Angola) y el Instituto Superior Politécnico de Manica (en Mozambique). El objetivo es mostrar cómo las dos instituciones han contribuido al desarrollo local y, por consiguiente, nacional, con su oferta formativa y mostrando sus trabajos de graduación. En este estudio de casos múltiples se realizó una investigación bibliográfica y documental, además de un estudio de los documentos institucionales. Los resultados muestran que las dos instituciones han contribuido a la capacitación del personal y a la especialización de la mano de obra, a través de sus títulos. En esa investigación se destacaron las obras de fin de curso dirigidas a múltiples beneficiarios y que aportan beneficios de investigación, así como las sugerencias de mejoras factibles para aumentar la productividad, la calidad, la eficacia y la eficiencia de los diversos recursos disponibles para lograr un mayor impacto en el desarrollo local y, por consiguiente, nacional.

Palabras clave: África subsahariana; Desarrollo nacional; Educación; Educación superior angoleña; Educación superior mozambiqueña.

\section{INTRODUÇÃO}

A África Subsariana é uma região rica em recursos, por exemplo, detém 7\% das reservas de petróleo do mundo e importantes reservas de fosfato, cobre e cobalto, além da indústria de turismo que está em desenvolvimento. Paradoxalmente, esta parte da África é uma das regiões mais pobres do mundo com altos índices de mortalidade infantil, analfabetismo e baixa expectativa de vida.

Projeções do Banco Mundial para 2030, indicam que em cada dez pessoas em situação de pobreza extrema, nove viverão nos países da Africa Subsariana (Banco Mundial, 2019). Para piorar a situação, a pandemia da Covid-19 veio agravar esta realidade de extrema pobreza, visto que mais de $63 \%$ da população da África Subsariana vive da agricultura de subsistência nas zonas rurais.

Para inverter este triste cenário, há uma aposta na educação, que é vista como o alicerce de desenvolvimento socioeconómico e político de cada região. Desenvolvimento, segundo Oliveira (2002, p. 40) "nada mais é que o crescimento incrementos positivos"; para este autor (id., p. 38) o desenvolvimento, "em qualquer 
conceção, deve resultar do crescimento económico acompanhado de melhoria na qualidade de vida", nos casos deste estudo o desenvolvimento é mais verificável nas comunidades beneficiárias envolventes.

Correia (2007) refere que nos países na fase pós-colonial, a educação conservase como um recurso fundamental para o seu desenvolvimento, sendo um meio de transferência de valores que possibilita a emergência de um novo homem.

$\mathrm{Na}$ educação destaca-se o Ensino Superior (ES), que tem vindo a dar o seu contributo para o desenvolvimento da África Subsariana. Neste estudo foca-se Angola e Moçambique, países que têm especialmente em comum serem duas ex-colónias portuguesas, que começaram o ES nos seus territórios com base no mesmo decreto de lei (n. 44.530, de 21 de agosto de 1962), ambos independentes em 1975, países de língua oficial portuguesa, logo pertencentes à Comunidade de Países de Língua Portuguesa (CPLP) e Países Africanos de Língua Oficial Portuguesa (PALOP); e nações que passaram por um conflito armado interno pós-independência que dificultou o desenvolvimento nacional, o qual se almeja progredir na presente época de paz e reconstrução territorial.

Pretende-se apresentar dois exemplos dessa contribuição do ensino superior mostrando os casos de duas Instituições de Ensino Superior (IES): Escola Superior Politécnica do Namibe (ESPtN $\left.{ }^{3}\right)$ - Angola e Instituto Superior Politécnico de Manica (ISPM) - Moçambique. Assim, tem-se como objetivo mostrar como as duas IES têm contribuído para o desenvolvimento local, e consequentemente nacional, com a sua oferta formativa e os Trabalhos de Fim de Curso (TFC) de licenciatura. Para a realização deste objetivo faz-se uma pesquisa bibliográfica e documental neste estudo múltiplo de caso, para além de um estudo de documentos institucionais.

\section{EXPANSÃO DO ENSINO SUPERIOR EM ANGOLA E MOÇAMBIQUE}

Nas antigas colónias portuguesas a política educativa não fazia diferenciação de territórios. No tempo colonial os estudos superiores eram efetuados na metrópole. Campos \& Lima (2012) comentam que nessa época quem vivia nas colónias e aspirava fazer um curso superior, e conseguia realizar essa faceta, era uma minoria composta

\footnotetext{
${ }^{3} \mathrm{~A}$ sigla oficial inclui um " $\mathrm{t}$ " minúsculo para diferenciar da sigla de outra escola. 
por filhos de assimilados com maiores posses financeiras ou aqueles que eram sustentados por missões religiosas. Estes rumavam a Lisboa, Coimbra e Porto, cidades desconhecidas para a maioria e onde poucos tinham qualquer apoio familiar.

Pelo referido Decreto de Lei $\mathrm{n} . \underline{\text { 44.530, de }} 21$ de agosto de 1962, da Administração Portuguesa, dá-se o início do ensino superior em Angola e Moçambique com os Estudos Gerais Universitários (EGU). Os estudos universitários eram principiados nas colónias, contudo tinham que ser concluídos na metrópole.

Até 1974 havia um número relativamente reduzido de estudantes nas duas colónias: em Moçambique, "havia 3.800 estudantes universitários, dos quais apenas 40 negros" (Bouene, 2005, p. 70). Em Angola eram cerca de 2.354 estudantes universitários, segundo Teta (s. d.).

Após as esperadas independências em 1975, os conflitos civis posteriores dificultaram o sucesso das políticas educativas dos novos países, ficando os resultados muito aquém das expetativas nacionais.

Em 1992 findou o conflito armado em Moçambique (Instituto Nacional de Estatística [de Moçambique], 2013). A paz chegou mais tarde em Angola, em 2002. Em ambos os países, a paz permitiu uma evolução muito significativa nos sistemas educativos (Patatas, 2019, p. 37). Desde então o ensino superior sofre uma grande expansão, que mostra a preocupação dos governos dos dois países em aumentar e expandir este nível de ensino nestes países para incrementar os seus benefícios, sendo um deles o desenvolvimento nacional. No período pós-paz, que se refere ao período após assinaturas dos acordos de paz que colocaram o fim dos conflitos armados internos, sendo em 1992 e 2002 para Moçambique e Angola respectivamente:

- Em Angola houve uma "rápida progressão da oferta de ensino superior, público e privado" (Governo da República de Angola, 2012, p. 37).

- Acerca de Moçambique, Senete $(2015$, p. 1) declara que:

nos últimos anos, o ensino superior é caracterizado por uma galopante expansão de instituições superior públicas e privadas facto que alarga ainda mais a base de oferta do ensino superior aos cidadãos, como forma de manter uma sociedade sã e rica de conhecimentos básicos que possam conduzir a um desenvolvimento satisfatório para a comunidade ou sociedade em geral. 
Contudo, a oferta em ambos os países deste nível de estudos não é suficiente para a demanda e a expansão não é transversal a todo o território nacional, mostrando a necessidade de investir e expandir esse subsistema de ensino, consubstanciando-se num desafio estatal.

Na Agenda 2063 da União Africana, a educação em geral e o ES em particular, são "uma área de intervenção prioritária para cumprir a aspiração da prosperidade baseada no crescimento inclusivo e no desenvolvimento sustentável" (Governo de Angola, 2018, p. 74).

\section{ENSINO SUPERIOR EM ANGOLA}

A independência nacional trouxe uma grande instabilidade em todos os sectores, incluindo o da educação. No ensino superior, por exemplo, desencadeia um êxodo de professores, enfraquecendo os quadros universitários nacionais. Como mencionado, a posterior guerra civil dificultou a aplicação das políticas educativas, as quais só encontram um ambiente propício de desenvolvimento após a paz nacional.

Angola passou uma evolução quantitativa de IES públicas: em 2009 existia apenas uma Universidade pública (Universidade Agostinho Neto - UAN); no ano letivo de 2014 eram 64; em 2015 constituíam 73 e em 2019 existiam 78 IES 4 . Apesar deste incremento institucional ainda é reduzida a oferta universitária em grande parte das 18 províncias nacionais (Governo da República de Angola, 2012).

Em 2020 está a acontecer uma reorganização da rede de IES públicas com base no Decreto Presidencial 285/20, de 29 de outubro, com a seguinte base:

A organização da Rede (...) estabelecida pelo Decreto 7/09 de 12 de Maio, não tem revelado alinhamento com um Plano de Desenvolvimento Económico Regional do País. Havendo necessidade de se proceder à organização da Rede de Instituições Públicas de Ensino Superior, com base na reorganização de recursos existentes, com o objectivo de atender às necessidades de desenvolvimento nacional, bem como enquadrar novas iniciativas de criação de Instituições Públicas de Ensino Superior (p. 5308).

\footnotetext{
4 Jornal de Angola de 25 Fevereiro de 2019. Disponível em: http://www.angop.ao/angola/pt_pt/noticias/educacao/2019/1/9/Instituicoes-ensino-superior-devemobedecer-padroes-internacionais,c8f73d8b-3252-442a-a689-23a2c3d59e25.html, consultado a $30 / 06 / 2020$.
} 
Com este fundamento está em fase de implementação o redimensionamento de instituições já existentes ou fusão de algumas delas e a criação de mais 3 universidades públicas. É de notar que em todas as alterações do subsistema do ES ocorridas fazem-se sempre menção à necessidade de o ajustar às necessidades do desenvolvimento do país, como se pode ver também nesta última reorganização na citação acima. Este assunto será retomado mais adiante.

\section{ENSINO SUPERIOR EM MOÇAMBIQUE}

Depois da Independência de Moçambique em 1975, à única IES, Universidade de Lourenço Marques (ULM), foi atribuída o nome de Universidade Eduardo Mondlane (UEM). Esta sofreu transformações notáveis desde então, tendo a guerra civil de 1977 a 1992 dificultado o seu desenvolvimento. Só em 1985 se fundou a segunda IES, a Universidade Pedagógica.

Devido às mudanças políticas e económicas nos anos 90 mais instituições públicas e privadas do ES foram criadas, e passando uns 30 anos da constituição da democracia multipartidarismo e 58 anos desde a primeira IES em Moçambique, hoje existe cerca de 53 IES no país, dos quais 22 são públicas e 31 privadas, entre Universidades, Institutos, Escolas Superiores e Academias (MCTESTP, 2019).

A expansão do ES preconizada no Plano Estratégico 2000-2010 do sector visava expandi-lo para as províncias que ainda careciam deste nível de ensino, com vista a "expandir as oportunidades de acesso ao ensino superior em harmonia com as necessidades crescentes do mercado de trabalho e da sociedade de modo a que mais cidadãos moçambicanos pudessem adquirir e desenvolver conhecimentos e capacidades necessárias a um rápido desenvolvimento económico e social" (PEES 2000-2010, citado por Massinga, et al. 2015, p. 2).

É neste período que cresce a diversificação do ES, com a criação de Institutos Superiores Politécnicos (Decreto № 31/2005, de 23 de Agosto), estes virados para o saber fazer, de modo a contrariar o pensamento comum "formar um trabalhador com muita teoria, sobretudo nos cursos de licenciatura, e sem a devida inserção no mundo do trabalho" (Tambe, Gôuvea \& Tasmerão, 2019, p. 9).

Por sua vez, o Plano Estratégico do Ensino Superior (PEES) 2012-2020 indica como visão do ES em Moçambique "um ES em expansão, com equilíbrio e qualidade, 
sob uma governação eficiente e respeitadora da autonomia das instituições que, guiando-se pelo princípio da democraticidade, desenvolvam atividades produtoras de conhecimento e que seja objeto de reconhecimento nacional e internacional" (PEES, 2012, p. 9).

Em 2019, o ES moçambicano completou 57 anos de existência, formando mais licenciados do que outros graus, e de acordo com Tambe, Gôuvea \& Tasmerão (2019, p. 3), "esse marco oferece-nos uma oportunidade para pensarmos sobre a comparticipação do ES no desenvolvimento do país".

\section{IMPORTÂNCIA DO ENSINO SUPERIOR NO DESENVOLVIMENTO NACIONAL}

Segundo Patatas (2017, p. 57),

o desenvolvimento de um país é mutidimensional, complexo, transversal e envolve diversas variáveis endógenas e exógenas (ao país). Por isso, não há uma relação direta e mensurável entre educação e desenvolvimento nacional. Todavia, variados estudos revelam o papel positivo da educação no desenvolvimento, trazendo às sociedades benefícios multisetoriais, duráveis e impactantes.

O propósito mais reconhecido da universidade é o formativo, e esse é manifestamente indispensável nos países mais pobres e os em desenvolvimento:

é sua tarefa, também, formar no domínio técnico e profissional, as suas futuras elites e diplomados de nível médio e superior de que os países necessitem, para poderem sair do ciclo da pobreza e de subdesenvolvimento em que se encontram (Delors, 1996, p. 24).

Neste âmbito, "o impacto do Ensino Superior no desenvolvimento de um país muda de intensidade, dependendo do papel atribuído à universidade, em cada contexto geográfico" (Patatas, 2017, p. 61). Sobre África, e neste campo, Correia (2007, p. 48) comenta:

a importância do crescimento do saber no processo social em África decorre do nível estatuário e da elevação na hierarquia social dos elementos escolarizados. Esta aliança entre o saber e o poder vinda da época colonial ganha um novo impulso nos Estados pós-colonial. [...] As populações escolarizadas e, sobretudo, os diplomados universitários, 
encontravam-se em posição privilegiada para desempenhar altos cargos de responsabilidade.

\section{EM ANGOLA}

O desenvolvimento nacional esteve sempre interligado com o ES, como já mencionado anteriormente, e depende deste para a sua efetivação. De acordo com a UTG/PNFQ 5 (2015, p. 29), para a concretização do Plano Nacional de Quadros (PNFQ) 2013-2020, deve haver "uma aposta forte na formação de angolanos para o desenvolvimento do País".

Essa necessidade é confirmada, por exemplo, nestes dados: em 2010 dos recursos humanos apenas $5 \%$ tinham o ensino superior, mas para "o desenvolvimento socioeconómico sustentável, os Recursos Humanos do país devem ser constituídos (...) por uma percentagem de Quadros Superiores de cerca de $10 \%$ " (id., p. 14), estão previstos 8\% para 2020.

Outra referência do papel do ES no desenvolvimento nacional é feita na finalidade da reorganização da rede de IES, que está atualmente a decorrer (Artigo 3ํ, do Decreto Presidencial 285/20 de 29 de outubro).

a Reorganização da Rede de Instituições Públicas de Ensino Superior tem como finalidade a sua expansão ordenada e adequação aos objetivos estratégicos do desenvolvimento económico, social, tecnológico $e$ comunitário, no território em que está inserida [grifo nosso], em conformidade com os programas do Executivo (p. 5308).

O Ensino Superior é mencionado na Estratégia de Desenvolvimento a Longo Prazo (ELP) "Angola 2025" por uma política singular, que visa: "promover o desenvolvimento humano e educacional do povo angolano" (Governo de Angola, 2018, p. 74). O ambicionado é que seja garantida a "formação de recursos humanos qualificados e altamente qualificados, necessários ao desenvolvimento da economia, inovação e conhecimento, melhorando substancialmente a formação média e superior e a formação avançada" (Governo de Angola, 2018, p. 74).

\footnotetext{
${ }^{5}$ Unidade Técnica de Gestão do Plano Nacional de Formação de Quadros - UTG/PNFQ (2015). 


\section{EM MOÇAMBIQUE}

A educação consta na Prioridade II (Desenvolver o Capital Humano e Social) do Plano Quinquenal do Governo moçambicano (PQG 2015-2019). Esta Prioridade define o capital humano e social como "um conjunto de capacidade, conhecimentos, competências e atributos de personalidade individual e coletiva que favorecem a realização de atividades sociais e económicas necessárias para o desenvolvimento socioeconómico sustentável e integrado do País" (PQG, 2015, p. 11).

No seu objetivo estratégico (i), a Prioridade II, visa "promover um Sistema Educativo inclusivo, eficaz e eficiente que garanta a aquisição das competências requeridas ao nível de conhecimentos, habilidades, gestão e atitudes que respondam às necessidades de desenvolvimento humano" (PQG, 2015, p. 12). Para concretização do objetivo (i), o ES desempenha um papel fundamental no desenvolvimento do País através da sua oferta formativa, pesquisa e extensão.

\section{DESENVOLVIMENTO DAS COMUNIDADES ATRAVÉS DE TRABALHOS DE FIM DO CURSO DE LICENCIATURA}

Este estudo compartilha o contributo do ES para o desenvolvimento na África Subsariana: casos de Angola e Moçambique através dos TFC de licenciatura em duas IES: ESPtN (Angola) e ISPM (Moçambique).

Para ambas as instituições, o TFC refere-se a uma monografia científica que é produzida pelo estudante no final dos quatro anos de formação para o nível de Licenciatura. A monografia é o trabalho de investigação apresentado e defendido pelo estudante perante um júri e com a finalidade de obtenção do grau académico de licenciatura. Consiste na implementação de um projeto de pesquisa, coleta de dados e a apresentação dos resultados seguindo a metodologia científica e as sugestões apresentadas têm de ser exequíveis, para demonstrar as competências adquiridas pelo estudante ao longo da sua formação académicas.

\section{CASO DA ESPTN, ANGOLA}

A primeira IES na província do Namibe foi a Escola Superior de Ciência e Tecnologia, para estudos apenas no nível do bacharelato, iniciando o seu 
funcionamento no ano letivo de 2005. Mudou posteriormente de designação, em 2009, para Escola Superior Politécnica do Namibe (ESPtN), quando passou a pertencer à Região Académica VI, Universidade Mandume ya Ndemufayo (UMN). Em 2012 principia o nível de licenciatura dos seus cursos: Biologia Marinha, Contabilidade e Gestão, Engenharia Ambiental, Engenharia Elétrica e Engenharia Mecânica, em 2014 começou o de Engenharia Metalúrgica e de Materiais.

A ESPtN está em reestruturação decorrente da sua recente integração na nova Universidade do Namibe, criada pelo Decreto Presidencial 285/20 de 29 de outubro. A evolução nos licenciados está espelhada no Quadro 1.

Quadro 1. Licenciados da ESPtN

\begin{tabular}{|c|c|c|c|}
\hline Ano & Número de & \multicolumn{2}{|c|}{ Género/Sexo } \\
\cline { 3 - 4 } & Licenciados & Masculino & Feminino \\
\hline 2014 & 60 & 51 & 9 \\
\hline 2015 & 126 & 96 & 30 \\
\hline 2016 & 145 & 102 & 43 \\
\hline $2017^{*}$ & 150 & 95 & 55 \\
\hline 2018 & 226 & 134 & 92 \\
\hline 2019 & 374 & 195 & 179 \\
\hline Total & 1081 & 673 & 408 \\
\hline
\end{tabular}

Nota: Primeiro ano com licenciados no curso de Engenharia Metalúrgica e Materiais. Fonte: Área académica institucional, Março 2020.

A oferta formativa desta IES emergiu com o alvo de colmatar algumas lacunas detetadas de quadros no tecido laboral e no uso de mão de obra local, consequentemente grande parte dos quadros atuais passaram por esta IES ou são licenciados ali, mostrando nesta vertente o seu contributo para o desenvolvimento provincial.

Para além disso, esta IES apoia as entidades, organizações, empresas, etc com os TFC de licenciatura, especialmente nas investigações e nas respetivas sugestões de melhoria contida nas mesmas. Estas sugestões podem ser de variada tipologia: organização, gestão, conservação, prevenção, atendimento, na área dos diferentes recursos, manutenção, criação de áreas ou serviços, infraestruturas, materiais, segurança e higiene no trabalho, maquinaria, remodelação, reestruturação, desenho e projetos, etc. que no conjunto contribuíram para o impacto desse beneficiário direto e 
naturalmente para o desenvolvimento local. Os principais beneficiários foram segundo o Quadro 2 abaixo:

Quadro 2 - Beneficiários dos TFC

\begin{tabular}{|c|c|c|c|c|c|c|}
\hline \multirow{2}{*}{ Beneficiários Diretos } & \multicolumn{6}{|c|}{ TFC das Licenciaturas dos Cursos } \\
\hline & BM & CG & EA & EE & EM & EMM \\
\hline Cooperativas & $\mathrm{X}$ & $\mathrm{X}$ & & $\mathrm{X}$ & & \\
\hline Empresas e fábricas do sector pesqueiro & $\mathrm{X}$ & $X$ & & $X$ & $\mathrm{X}$ & \\
\hline $\begin{array}{l}\text { Pescadores, vendedores de peixe e } \\
\text { Mercado do peixe }\end{array}$ & $X$ & & $X$ & & & \\
\hline $\begin{array}{l}\text { Zona pesqueira, praias, portos, costa, } \\
\text { baías }\end{array}$ & $x$ & & $x$ & $x$ & & \\
\hline Bombeiros, polícia, prisões & $\mathrm{X}$ & $\mathrm{X}$ & $\mathrm{X}$ & $\mathrm{X}$ & & \\
\hline Municípes, povos, comunidade em geral & $x$ & $x$ & $x$ & $x$ & $\mathrm{X}$ & $x$ \\
\hline Turistas & $\mathrm{X}$ & $\mathrm{X}$ & $\mathrm{X}$ & & & $\mathrm{X}$ \\
\hline Indústrias diversas e seus trabalhadores & $\mathrm{X}$ & $\mathrm{X}$ & $\mathrm{X}$ & $\mathrm{X}$ & $\mathrm{X}$ & \\
\hline $\begin{array}{l}\text { Escolas, professores, demais funcionários } \\
\text { e estudantes }\end{array}$ & $\mathrm{x}$ & $x$ & $\mathrm{x}$ & $x$ & $X$ & $X$ \\
\hline $\begin{array}{l}\text { Empresas públicas, seus serviços, clientes, } \\
\text { consumidores e seus trabalhadores }\end{array}$ & $X$ & $X$ & $x$ & $x$ & $X$ & $X$ \\
\hline $\begin{array}{l}\text { Empresas privadas, seus serviços, } \\
\text { clientes, consumidores e reus } \\
\text { trabalhadores }\end{array}$ & $x$ & $x$ & $x$ & $x$ & $x$ & $X$ \\
\hline $\begin{array}{l}\text { Hospitais, Centros de saúde, Laboratórios, } \\
\text { e seus trabalhadores, doentes e utentes }\end{array}$ & & $x$ & $x$ & $x$ & $X$ & $x$ \\
\hline $\begin{array}{l}\text { Fazendas, fazendeiros e seus funcionários } \\
\text { (agricultura, gado e outros animais, solos) }\end{array}$ & & $x$ & $x$ & $x$ & & \\
\hline $\begin{array}{l}\text { Reservas ambientais, parques, espaços } \\
\text { públicos }\end{array}$ & $x$ & & $x$ & & & $x$ \\
\hline $\begin{array}{l}\text { Centrais térmicas, termoelétricas e de } \\
\text { resíduos }\end{array}$ & & & & $x$ & $x$ & $x$ \\
\hline $\begin{array}{l}\text { Centralidades, povoados, bairros, ruas, } \\
\text { edifícios, cemitérios }\end{array}$ & & $x$ & $x$ & $x$ & $X$ & \\
\hline $\begin{array}{l}\text { Empresas de transportes, oficinas, seus } \\
\text { trabalhadores, condutores, utilizadores } \\
\text { de transportes, condutores }\end{array}$ & & $x$ & & $x$ & $x$ & $X$ \\
\hline $\begin{array}{l}\text { Estabelecimentos de conservação ou } \\
\text { comercialização e seus trabalhadores }\end{array}$ & $x$ & $x$ & $x$ & $x$ & $x$ & $x$ \\
\hline
\end{tabular}

Cursos: $\mathrm{BM}=$ Biologia Marinha, $\mathrm{CG}=$ Contabilidade e Gestão, $\mathrm{EA}=$ Engenharia Ambiental, $\mathrm{EE}=$ Engenharia Elétrica, $\mathrm{EM}=$ Engenharia Mecânica, $\mathrm{EMM}=$ Engenharia Metalúrgica e de Materiais.

Fonte: Biblioteca - acervo documental institucional ${ }^{6}$

\footnotetext{
${ }^{6}$ Para a recolha destes dados agradece-se o apoio de Nelson Cunha.
} 
Como se pode verificar pelo quadro acima, praticamente todos os sectores e grupos sociocomunitários beneficiaram directamente dos TFC de licenciatura da ESPtN, sendo estes um contributo muito significativo para o desenvolvimento local e consequentemente nacional.

\section{CASOS DO ISPM, MOÇAMBIQUE}

O Instituto Superior Politécnico de Manica (ISPM) é uma instituição de ensino superior técnico profissional pública fundada em 2005, por Decreto № 31/2005, de 23 de Agosto. A instituição tem por missão:

contribuir no desenvolvimento sustentável das comunidades onde se encontra inserido, através do ensino técnico profissional, com princípios e valores institucionais que dentre outros respeitam a diversidade e equidade no acesso às oportunidades (Estatutos do ISPM, 2006).

A criação do ISPM, junto os outros 2 Institutos Superiores Politécnicos - ISPs (Gaza e Tete) em 2005, baseou-se "na compreensão dos contextos sócio-economicos e educacionais gerais do país, e no facto do sistema de ensino superior vigente até então ser ainda pequeno e pouco diversificado, oferecendo poucas oportunidades de formação técnico-profissional a nível superior, e, tendo por isso dificuldades de responder às necessidades de uma economia em expansão e desenvolvimento" (Massinga et al, 2015, p. 1).

Nexte contexto, o ISPM foi criado para responder a demanda da região potencialmente agrícola, nisto o primeiro curso a ser ministrado em 2006 foi a Licenciatura em Engenharia Agrícola - opção Agro-Negócios. Seguiu outros cursos do ramo agrário como Engenharia Florestal (2007) e Engenharia Zootécnica (2008), e de Contabilidade e Auditoria em 2008, de Ecoturismo e Gestão de Fauna Bravia 2010. Introduziu ainda em 2015 e 2016 os cursos de Tecnologia de Processamente de Alimentos e Biotecnologia, respectivamente contando até então com 7 Cursos de Licenciatura, além de dois Cursos de Mestrado em consórcio com outras Universidades.

Estando localizado num Posto Administrativa com residentes meramente agricultores de subsistências, uma das grandes contribuições do ISPM na elevação do 
nível de vida das comunidades locais é a contratação de jovens que vivem ao redor do Campus para trabalhos sazonais na Farma e na manutenção do Campus.

Desde a sua primeira graduação em 2010 de apenas 65 licenciados em Engenharia Agrícola, o ISPM já graduou até então 829 licenciados nos seus cinco cursos com a exceção dos cursos de Tecnologia de Processamento de Alimentos e Biotecnologia, como se pode observar no Quadro 3.

Quadro 3 - Licenciados do ISPM de 2010 a 2019

\begin{tabular}{|c|c|c|c|}
\hline Ano & Número de & \multicolumn{2}{|c|}{ Género/Sexo } \\
\cline { 3 - 4 } & Licenciados & Masculino & Feminino \\
\hline 2010 & 65 & 52 & 13 \\
\hline 2012 & 108 & 80 & 28 \\
\hline 2015 & 140 & 104 & 36 \\
\hline 2016 & 162 & 93 & 69 \\
\hline 2018 & 197 & 111 & 86 \\
\hline 2019 & 157 & 94 & 63 \\
\hline Total & $\mathbf{8 2 9}$ & $\mathbf{5 3 4}$ & $\mathbf{2 9 5}$ \\
\hline
\end{tabular}

Fonte: ISPM, 2020.

Os graduados do ISPM destacam-se no desenvolvimento da região, tanto no sector público e de extensão agrária como no sector privado criando suas próprias empresas e negócios, como ilustra o Quadro 4.

Quadro 4 - Contribuição dos graduados nos sectores de trabalho.

\begin{tabular}{|c|c|c|c|c|c|}
\hline \multirow[t]{2}{*}{ Beneficiários Diretos } & \multicolumn{5}{|c|}{$\begin{array}{c}\text { TFC das Licenciaturas dos } \\
\text { Cursos }\end{array}$} \\
\hline & EA & $E F$ & EZ & CA & EGFB \\
\hline $\begin{array}{l}\text { Empresas de produção, processamento, e venda } \\
\text { de carne, leite e seus derivados (MOZBEEF, } \\
\text { Pintos Agropecuária, Land'Olakes, Talho } \\
\text { Cafumpe, Tsetsera Butchery, Unguluzane } \\
\text { Agropecuária, Abílio Antunes, Agro Maco) }\end{array}$ & $\mathrm{x}$ & & $\mathrm{X}$ & $\mathrm{X}$ & \\
\hline Estação Zootécnica de Angónia, Guitas Chicken & & & $\mathrm{X}$ & & \\
\hline Açucareira de Mafambisse, BAGC & $\mathrm{X}$ & & & & \\
\hline Companhias de Sena, Vanduzi, Zambe & $\mathrm{X}$ & & & & \\
\hline $\begin{array}{l}\text { Direção Provincial de Agricultura e seguranca } \\
\text { alimemtar, SDAE-Vanduzi, Semoc }\end{array}$ & $\mathrm{X}$ & & & & \\
\hline $\begin{array}{l}\text { GAPI, IAV, IIAM, Laboratório da mosca, } \\
\text { EBENEZER }\end{array}$ & $\mathrm{X}$ & & & & \\
\hline Empresas, Serviços e Consultorias & & & & $X$ & \\
\hline
\end{tabular}




\begin{tabular}{|c|c|c|c|c|c|}
\hline $\begin{array}{l}\text { Contabilidade, Auditoria e Gestão (ADPP, ANE, } \\
\text { BDO, CCF, ITC, KPMG, New Star, OCAM, } \\
\text { Copoleite, Cosnoa Lda, Plasoc-Plataforma de } \\
\text { sociedade civil de Chimoio, Premier Milling, Lda, } \\
\text { Movitel, Prestcont - Chimoio) }\end{array}$ & & & & & \\
\hline $\begin{array}{l}\text { Conselhos municipais, Autoridade Tributária, } \\
\text { Bancos } A B C, B \mid M, B C l \text {, Letsego, }\end{array}$ & & & & $x$ & \\
\hline $\begin{array}{l}\text { Docentes Universitários (ISPM, UP, UCM, } \\
\text { ISPMutasa) }\end{array}$ & $\mathrm{X}$ & $\mathrm{x}$ & $\mathrm{X}$ & $\mathrm{x}$ & $\mathrm{X}$ \\
\hline Investigadores (ISPM, IIAM, UP, UCM) & $\mathrm{X}$ & $\mathrm{X}$ & $\mathrm{X}$ & & $\mathrm{X}$ \\
\hline Técnicos Superiores (ISPM, UniZambeze) & $\mathrm{x}$ & & & $x$ & \\
\hline Docentes do Ensino Secundário & & & $\mathrm{x}$ & & \\
\hline $\begin{array}{l}\text { Direção Provincial de Trabalho, DPCTEST, DPEF, } \\
\text { DPIC, INAS, Instituto de Deficientes Visuais, } \\
\text { STAE, Direção Provincial de Agricultura e } \\
\text { Segurança Alimentar }\end{array}$ & & & & $\mathrm{x}$ & \\
\hline $\begin{array}{l}\text { F. Redonda, Fabrica Refreg. Vumba, Fipag, } \\
\text { Enprecontas, Lda }\end{array}$ & & & & $x$ & \\
\hline $\begin{array}{l}\text { Empresas de exploração de madeira (IFLOMA, } \\
\text { IIAM, Inchope Madeiras, LEVASFLORE, MOFLOR, } \\
\text { EBENEZER, ORAM, TYT, CEFLOMA, CIPLA) }\end{array}$ & & $\mathrm{x}$ & & & \\
\hline CAM-Internacional & & & & & $\mathrm{X}$ \\
\hline Casa M'sika Lodge & & & & & $x$ \\
\hline DPTUR, Ecomicaia-Ndzou Camp & & & & & $\mathrm{X}$ \\
\hline Parque Nacional da Gorongosa & & & & & $\mathrm{x}$ \\
\hline $\begin{array}{l}\text { Programa Moz Bio-Zomba/Maronga, Programa } \\
\text { Tchuma Tchato }\end{array}$ & & & & & $\mathrm{X}$ \\
\hline Reservas de Chimanimani, Gilé, Marromeu & & & & & $X$ \\
\hline
\end{tabular}

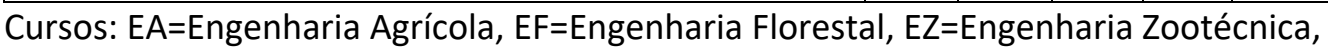
$\mathrm{CA}=$ Contabilidade e Auditoria, EGFB=Ecoturismo e Gestão de Fauna Bravia.

Fonte: ISPM, 2018.

Os dados acima indicam o comprometimento do ISPM em cumprir a sua missão de:

contribuir no desenvolvimento sustentável das comunidades onde se encontra inserido, através do ensino técnico profissional, com princípios e valores institucionais que dentre outros respeitam a diversidade e equidade no acesso às oportunidades.

Os graduados de licenciatura em cursos oferecidos pelo ISPM destacam-se na contribuição para o desenvolvimento na África Subsariana em áreas de saber fazer na Agricultura, Produção Animal, Produção e exploração de madeira, Contabilidade e Auditoria, Ecoturismo e Gestão de Fauna Bravia, entre outras. Para o desenvolvimento do capital humano, como demonstra a Tabela 4, existe no momento antigos 
estudantes do ISPM já como docentes e investigadores em quase todas IES da província de Manica, além dos Técnicos Superiores na gestão e administração dos Departamentos de Contabilidade, Auditoria, Gestão de Recursos Humanos, Laboratórios diversos, e nas Instituições Bancárias, entre outros sectores de atividades. Aliás, tem uma representação significativa dos graduados do ISPM no empreendedorismo, apoiados na área de negócios pelo Centro de Incubação de Empresas, principalmente na criação de frangos, consultorias de contabilidade e auditoria, agricultura, produção de peixes, produção e melhoramentos de sementes, guias turísticos, entre outras áreas.

\section{CONCLUSÕES}

Na África Subsariana, o ensino superior, de um modo geral, apresenta fortes limitações relacionadas a infraestruturas, corpo docente e fatores sociopolíticos. Entretanto, este subsistema de educação, se destaca no seu contributo para o desenvolvimento desta região do mundo através da sua oferta formativa, pesquisa e extensão comunitária.

Este estudo apresentou a contribuição de duas IES, uma em Angola e outra em Moçambique. Estes países, antigas colónias de Portugal, compartilham o mesmo panorama de desenvolvimento de ES, pois começaram este nível de ensino com base no mesmo decreto. O ES evoluiu e está em expansão em ambos os países, porém ainda aquém da procura estudantil deste nível de ensino, também não está suficientemente alargado a todas as províncias e municípios nacionais, contudo, apesar dos obstáculos e desafios, tem desempenhado o seu papel no desenvolvimento destes países.

Destaca-se neste estudo o contributo para o desenvolvimento local, regional e nacional dos TFC ao nível da licenciatura, como o grau que mais se forma nas duas IES: ESPtN e ISPM.

Para a ESPtN, que já formou 1081 licenciados, deu o seu contributo para a formação dos quadros locais e apoia as entidades, organizações, empresas, etc. com os TFC de licenciatura que visam múltiplos beneficiários, especialmente nas investigações e nas respetivas sugestões exequíveis de melhoria contida nas mesmas, com a 
finalidade de melhor uso dos variados recursos disponíveis de forma impactante que no seu conjunto contribui para o desenvolvimento local, regional e nacional.

O ISPM, que lançou no mercado de trabalho 829 licenciados desde-2010, se destaca no seu contributo notável em áreas de saber fazer dos seus cursos. Para o desenvolvimento do capital humano, existe no momento docentes, investigadores e técnicos superiores em IES da Província de Manica em vários setores. Através do seu Centro de Incubação de Empresas, o ISPM formou e apoiou os seus graduados em matéria de negócios, hoje os formados são empreendedores de sucesso em muitas áreas, que de um modo geral contribui evidentemente para o desenvolvimento socioeconómico da região.

Os resultados deste trabalho, e sinergia entre os dois países estudados, remete-nos a recomendar as IES a criarem bases de dados sobre o enquadramento e desempenho pós-formação do seu alumini de modo a avaliar efetivamente a qualidade e empregabilidade dos mesmos.

Neste âmbito, e para melhores resultados, sugere-se uma relação ainda mais estreita e produtiva entre universidade - empresas - comunidade, aumentando nomeadamente as parcerias e a comunicação, de modo a que estes três eixos possam estar mais ligados na deteção das necessidades locais e conjuntamente procurarem modo de colmatar ou reduzir os problemas que possam ser entraves e que retardam o almejado desenvolvimento regional.

Este é um trabalho inacabado, pois os dados aqui apresentados são uma pequena amostra e podem servir de base para estudos mais detalhados sobre a contribuição de outras IES, inclusive do ES em outras regiões dos países apresentados, como também de outros territórios da África Subsariana no aspirado desenvolvimento desta região rica em recursos, todavia considerada a mais pobre do planeta.

\section{REFERÊNCIAS}

BANCO MUNDIAL. Nove em cada dez pobres vão viver em África em 2030. Disponível em https://www.google.com/amp/s/observador.pt, consultado em 17/09/2020.

BOUENE, F. Moçambique: 30 anos de independência. Africana Studia. Rev. Internacional de Estudos Africanos, Universidade do Porto. (8), 69-84, 2005.

CAMPOS, G. A. G. \& Lima, M. C. Mobilidade académica internacional e a transformação das práticas pedagógicas na direção da transculturalidade, a 
experiência de estudantes originários dos países de língua portuguesa. Revista: Ensino Superior, 45- out./nov. e dez. 2012, 35-45, 2012.

CORREIA, V. Educação e Desenvolvimento. Lisboa: Colibri, 2007

DECRETO № 31/2005 de 23 de agosto, Conselho de Ministros, Maputo, Moçambique.

DECRETO PRESIDENCIAL 285/20, de 29 de outubro. Diário da República, I Série, no 173. Luanda. Estabelece a Reorganização da Rede de Instituições Públicas de Ensino Superior - Revoga o Decreto no 5/09 de 7 de abril.

DELORS, J. Educação: um tesouro a descobrir. Relatório para a UNESCO da Comissão Internacional sobre Educação para o século XXI. UNESCO. RioTinto: Asa, 1996.

GOVERNO DE ANGOLA. Sumário Executivo: estratégia Nacional de Formação de Quadros [ENFQ]. Luanda: autores, 2012.

GOVERNO DE ANGOLA. Plano de Desenvolvimento Nacional 2018-2022. Luanda: Ministério da Economia e Planeamento, 2018.

GOVERNO DE MOÇAMBIQUE. Plano Quinquenal do Governo 2015-2019. Maputo, 2015.

INSTITUTO NACIONAL DE ESTATÍSTICA [MOÇAMBIQUE]. Moçambique: Inquérito Demográfico e de Saúde 2011. MEASURE DHS/ICF International. Maputo: Ministério da Saúde, 2013.

INSTITUTO SUPERIOR POLITÉCNICO DE MANICA. Estatutos do Instituto Superior Politécnico de Manica, Matsinho. Distrito de Vanduzi. Moçambique, 2006.

INSTITUTO SUPERIOR POLITÉCNICO DE MANICA-ISPM. Balanço do Plano Estratégico 2013-2017. Matsinho, Moçambique, 2018.

INSTITUTO SUPERIOR POLITÉCNICO DE MANICA-ISPM. Dados dos graduados 2010-2019. Matsinho, Moçambique, 2020.

INSTITUTO SUPERIOR POLITÉCNICO DE MANICA-ISPM. Manual para apresentação dos trabalhos académicos. Matsinho, Moçambique, 2016.

MARIO, et al, Breve história do ensino superior em Moçambique, 2003. Disponível em https://circulodesociologia.wordpress.com/breve-historia-do-es-emmocambique/, consultado em 05/06/2020.

MASSINGA, R. A., VEREMU, G. \& MASSINGA, A. P. Qualidade e Avaliação Institucional das Instituições do Ensino Superior: A Longa Caminhada Rumo a Qualidade"- O Dilema das Novas Instituições: O Caso do Instituto Superior Politécnico de Manica (ISPM), 2015. In Livro de Atas, 5ạ Conferência FORGES, Universidade de Coimbra, Portugal, 18,19 e 20 de novembro, 54.

MINISTÉRIO DA CIÊNCIA E TECNOLOGIA, ENSINO SUPERIOR E TÉCNICO PROFISSIONAL - MCTESTP (2018) Instituições de Ensino Superior em Moçambique, 2018. Disponível em https://www.mctestp.gov.mz, consultado em 05/10/2020

MINISTÉRIO DA EDUCAÇÃO. Plano Estratégico de Ensino Superior 2012-2020. Maputo, 2012.

OLIVEIRA, G. B. Uma discussão sobre o conceito de desenvolvimento. Revista da FAE, maio/ago 2002. Curitiba, v.5, n.2, p. 37-48.

PATATAS, T. A. O papel do ensino superior no desenvolvimento de Angola: 0 caso da ESPtN. Revista FORGES (Fórum da Gestão do Ensino Superior nos Países e Regiões de Língua Portuguesa), 2017. vol. 5, n. 2, p. 55-70. 
PATATAS, T. A. Perceção Estudantil sobre o Insucesso Académico em Países de Língua Oficial Portuguesa: Caso de Angola e Moçambique. Revista FORGES, vol. 6, n. 1, (Bi-Anual-2019), 31-49. Disponível em http://www.aforges.org/wp-

SENETE, D. E. S. C. Causas do abandono escolar universitário. Estudo de caso: Faculdade de Engenharia da Universidade Católica de Moçambique, Chimoio, 20082012. Dissertação de mestrado, Universidade Católica de Moçambique, 2015.

TEMBE, T. A. F.; GOUVÊA, F. C. F. \& TASMERÃO, A. S. Educação Superior em Moçambique: Entre o estado e a astúcia do capital. Jornal de Políticas Educacionais. V13. N. 33. Setembro de 2019.

TETA, J. S. (s. d.). Educação superior em Angola. Disponível em: www.pucrs.br/edipucrs/cplp/arquivos/teta.pdf, consultado em 11/01/2020.

UNIDADE TÉCNICA DE GESTÃO DO PLANO NACIONAL DE FORMAÇÃO DE QUADROS - UTG/PNFQ (2015). Plano Nacional de Formação de Quadros [PNFQ] 20132020: Formar para a Realidade, Formar com Qualidade. Luanda: Gabinete de Comunicação e Imagem da UTG/PNFQ. 